\title{
A REVIEW ON CONGESTION MANAGEMENT IN RESTRUCTURED MARKET
}

\author{
Sumit Sharma ${ }^{1}$, Mandeep Boora ${ }^{2}$, Raminder Kaur $^{3}$ \\ ${ }^{1}$ Department of Electrical, PEC University of Technology, Chandigarh, India \\ ${ }^{2}$ Department of Electrical, PEC University of Technology, Chandigarh, India \\ ${ }^{3}$ Department of Electrical, PEC University of Technology, Chandigarh, India
}

\begin{abstract}
With the increase in competition there is very much a need of restructuring the system to get better power with higher efficiency and minimum losses. Consumer demand increases and due to this, there is overcrowding of transmission lines and so congestion occurs. Congestion is a critical issue and needs to be managed effectively. Congestion generally occurs in transmission and distribution systems and main factors leading to congestion are load shedding, generation failure, line outages etc. This paper discusses some of the useful methods for congestion management in restructured market.
\end{abstract}

Keywords-: Congestion, Restructuring, Locational Marginal Pricing, Optimal power flow (OPF), Load shedding, Independent power producer (IPP), Independent system operator (ISO).

\section{INTRODUCTION}

Transmission system is the major component of power industry. Regulated industry is the one where only one entity generates, transmits and distributes power but with the increase in consumer demand and competitive market there is a need of privatization or restructuring the power system. In restructuring of power system the system is divided in three main parts as gencos, transcos and discos [2]. These are three main agencies gencos as generation company, transcos as Transmission Company and discos as distribution company. There are a lot of advantages of deregulation as it encourages the competition. Deregulation avoids the monopoly in the market and here consumer gets the best quality of power at cheaper rates. In competitive industry congestion problem occurs because of limitation of line to accommodate all the power demand [1].

\section{RESTRUCTURING MARKET}

Restructuring is the process to change the power market according to the current scenario. As we came know, the term restructuring firstly was coined by the United States of America and later on it came in the market in Norway, Australia etc. but in these countries it was used only for design and infrastructure. In regulated markets, there is only one source for generating, transmitting and distributing. Restructuring of power system means deregulating the system and system is sub divided into three main systems that are gencos, transcos and discos. Gencos is generating company, transcos is transmission company and discos is distribution company [3]. The new technology is much better and more reliable. Restructuring of power system gives the better use of electricity. The main objectives of the deregulated markets are that the restructuring of power market gives the power to all consumers according to their demands. Restructuring of power system encourages the competition and also encourages the quality of electricity supply to the consumers. Due to the restructuring of power market there is much better flow of electricity and quality of the services. There are many benefits of the deregulation it avoids monopoly and encourages competition, consumer is assured good quality of power at a reasonable price. The system capacity is used very efficiently in restructured market. In deregulated market there is an optimization of energy supply. We discuss many methods which are very useful for mitigation of congestion.

Some of the main components of deregulated power system are:

\subsection{Independent Power Producer (IPP)}

An independent power producer is an entity which is not a type of public company. It is a utility which produces power for sale to private firms and end users. It is also called as non utility generator.

\subsection{Independent System Operator (ISO)}

It is the organization in a state especially in the United States which monitors and controls the electric grid of that state. There is a commission which takes care of this entity that is Federal Energy Regulatory Commission (FERC). This entity is formed on the direction of FERC. ISO is an independent body that ensures a flexible and a reliable power system.

There are different methods for congestion managements[6][15] like management of reactive power[18], voltage stability, load shedding [7], placements of FACT devices etc. but the above all methods manage the 
congestion from generation side but the new scenario needs congestion management from load side. Distributed generators are one of the good methods for congestion management because they help to manage the congestion from load side. With the deregulation congestion management becomes simple and can be managed quite easily. The method of distributed generators is most appropriate because of ease of installation and low cost. In this paper we present different techniques for congestion management and a review of restructuring of power system.

\section{CONGESTION MANAGEMENT METHOD}

The different methods used for congestion management are discussed. Nodal pricing, highest locational marginal pricing, difference between locational marginal pricing etc. are the main methods adopted for congestion management. Optimization is technique which is performed for reduction in generator cost and to maximize the benefits for the consumers.

\subsection{Nodal Pricing}

It is a technique to find out the prices where market clearing prices are to be found out for a large number of positions on the grid called nodes. Here every node represents the position on the transmission system where energy has to be injected by the generators. The price at each node shows the locational value of energy which includes the cost of energy and the cost of delivering it. Due to congestion all the stability limits are changed and so pricing has also to be changed. We have to take care of congestion management in nodal pricing because power flow is affected due to congestion.

\subsection{Locational Marginal Pricing}

For managing the transmission congestion there is a process called locational marginal pricing. In LMP method cost is calculated by the offers submitted by participants from the market and the cost from transmission usage is the increase in cost of the redispatch required to accommodate that transmission usage. If there exists a congestion in the systems, then at different position there is different LMP and when there is no transmission congestion there is zero charge for transmission usage. While calculating locational marginal pricing, factors taken into account are supply bids, demand offers and the physical aspects of the transmission including other operational constraints.

\subsection{Highest LMP Method}

Highest locational marginal pricing method is used for the placement of distributed generators in transmission for managing congestion [12]. Without congestion the LMP of all the buses are same but if there is a congestion in the system, these vary. In this method, after finding the LMP of all the buses we have to arrange them in priority order. The bus with highest LMP is ranked no. 1 and accordingly all the buses are arranged. To get the LMP of all the buses we place, distributed generators according to their LMP and so congestion is avoided to a great extent.

\subsection{LMP Difference Method}

Although Highest LMP method is a simple method but in certain cases by using this method a situation arises when congestion increases in the transmission line. So we can't say this method is more convenient and to avoid congestion another method LMP difference method that is more reliable and efficient [20]. In LMP difference method we have to find out the LMP of two buses and take their difference. To check the difference between LMP of different buses, we arrange them according to their priority and then select the position of distributed generators. This method is useful for managing the congestion, so this method is generally used more often in comparison to highest LMP method.

The distributed generators are placed at different positions of transmission line to avoid congestion but the size of distributed generators have not been considered and our main perspective is the reduction in the cost of the system. There is a different method to find the size of generators. It is to calculate the performance index. Performance index is based on the generator cost and is used to find size of the distributed generators.

\section{CONCLUSION}

In the restructured scenario of electricity market congestion management of transmission lines is difficult task. Congestion is a critical issue and have to be manage effectively. Different methods employed for congestion management which we described.

\section{REFERENCES}

[1]. Elango.K, Panjothi.S.R, Sharmeela.C, "Congestion Management In Restructured Power System," International journal of applied enginnering reasearch, Dindigul Vol.2, No.2,2011.

[2]. Fattahi Meyabadi, H.Barathi, M.Eshan,"Simultaneous Congestion Management And Cost Allocation In A Short Run Market Model," Iranian Journal Of Science \& Technology, Transaction B. Engineering Vol.31, No.B6, pp617-628 Printed In The Islamic Republic Of Iran, 2007

[3]. Vora Animesh," Congestion Management in Degulated Power System- A Review", International Journal of Science and Research vol.3 Issue 6, June 2014, pp 2237-2240

[4]. A. Kumar, S. C. Srivastava, and S. N. Singh, “A zonal congestion management approach using real and reactive power rescheduling,", IEEE Trans. Power Syst., Feb. 2004. [5]. A. J. Conejo, F. Milano, and R. Bertrand, " Congestion management ensuring voltage stability", IEEE Trans. Power Syst., 2006.

[6]. A. Kumar, S. C. Srivastava, and S. N. Singh, "Congestion management in competitive power market: A bibliographical survey," Elect. PowerSyst. Res., 2005.

[7]. A. Shandilya, H. Gupta, and J. Sharma, "Method for generation rescheduling and load shedding to alleviate line overloads using local optimization", in Proc. Inst. Elect. Eng., 1993.

[8]. A. Kumar, S. C. Srivastava, and S. N. Singh, “A zonal congestion management approach using ac transmission 
congestion distribution factors," Elect. Power Syst. Res., 2004.

[9]. F. Rahimi, and A. Ipakchi, "Demand response as a market resource under smart grid paradigm", IEEE Trans. Smart Grid, 2010.

[10]. J. Liu, M.M.A Salama, and R. R. Mansour, "Identify the impact of distributed resources on congestion management", IEEE Trans.Power Deliv. Jul. 2005.

[11]. K. Talukdar, A. K. Sinha, S. Mukhopadhyay, and A. Bose, "A Computationally simple method for costefficient generation rescheduling and load shedding for congestion management," Int. J. Elect. Power Energy Syst., Jun.-Jul. 2005.

[12]. M. Afkousi-Paqaleh, A. Abbaspour-Tehrani Fard, and M. Rashidinejad, "Distributed generation placement for congestion management considering economical and financial issues", Elect. Eng., 2010

[13]. N. Acharya, and N. Mithulananthan, "Locating series FACTS devices for congestion management in deregulated electricity markets", Elect.Power Syst. Res., 2007.

[14]. P. Boonyaritdachochai, C. Boonchuay, and W. Ongsakul, "optimal congestion management in an electricity market usingparticle swarm optimization with time-varying acceleration coefficients", Computersand Mathematics with Applications, 2010.

[15]. R. D. Christie, B. Wollenberg, and I. Wangensteen, "Transmission management in the deregulated environment," Proc. IEEE, Feb. 2000.

[16]. S. Dutta, and S.P. Singh, Optimal rescheduling of generators for congestion management based on particle swarm optimization, IEEETransactions on Power Systems, 2008.

[17]. Siddiqui A S, Sarwar M, Ahsan S, "Congestion management using improved inertia weight particle swarm optimization", IEEE PowerIndia International Conference (PIICON), New Delhi, 2014, 1-5

[18]. S. Hao, and A. Papalexopoulos, "Reactive power pricing and management", IEEE Trans. Power Syst., 1997.

[19]. S. N. Singh, and A. K. David, "Optimal location of FACTS devices for congestion management", Elect. Power Syst. Res. 2007.

[20]. K. Singh, V.K. Yadav,N.P.Padhy, and J. Sharma, “ Congestion management considering optimal placement of distributed generator in deregulated power system networks", Elec. Power Comp. Syst., vol. 42, no. 1, pp. 1322, Dec. 2014.

[21]. Sujatha Balaraman, N.Kamaraj, "Congestionmanagement in Deregulated power system Using real coded genetic Algorithm," International Journal of Engineering Science and Technology, Vol. 2(11), pp 6681-6690. 2010.

[22]. S. Surender Reddy, M. Sailaja Kumari and M. Sydulu, "Congestion Management in Deregulated Power System by Optimal Choice and Allocation of FACTS Controllers Using Multi-Objective Genetic Algorithm," Journal of Electrical Engineering \& Technology Vol. 4, No. 4, pp.467-475, 2009. [23]. L.I. Monforte, M.L.L. Casado, A.L. Baza, Y. Harmand, J-G Valentin and J.R. Perez, "Towards the Implementation of a Coordinated Congestion Management
Mechanism on the Spanish-French Interconnection: A Joint TSO Approach", 2 ${ }^{\text {nd }}$ CIGRE/ IEEE PES Symposium,57Oct.2005,pp.222-230.

[24]. P.G.M. Giesbertz, H.M. de Jong and J.C. Van der Lippe, “A Regulatory View on Market Integration and Cross Border Congestion Management", IEEE International Symposium CIGRE, 5-7Oct.2005, pp.148-155.

[25]. J.A. Aguado, V.H. Quintana, M. Madrigal and W.D. Rosehart, "Coordinated Spot Market for Congestion Management of Inter-Regional Electricity Markets", IEEE Transactions on Power Systems, Feb.2004, Vol.19, Issue1, pp.180-187.

[26]. K. Uhlen, L. Warland and O.S. Grande, "Model for Area Price Determination and Congestion Management in Joint Power Market", IEEE International Symposium CIGRE,5-7Oct.2005,pp 100-109.

[27]. K. Purchala, L. Meeus and R. Belmans, "Implementation Aspects of Coordinated Auctioning for Congestion Management", IEEE Bologna Power Tech Conference, 23-26June2003, Vol.4, pp5.

[28]. G. Yesuratnam, D. Thukaram "Congestion management in open access based on relative electrical distances using voltage stability criteria", Electric power systems research, vol. 77, pp. 1608-1618, 2007.

[29]. D. ThukaramH. P. Khincha, B. Ravi Kumar and G. Yesuratnam "Generators Contribution towards Loads and Line Flows - A Case Study” Power India Conference, 2006.

[30]. A.K. Singh, S.K. Parida, "Congestion management with distributed generation and its impact on electricity market”, Int. J. Elect. Power Energy Syst. 48 (2013) pp3947.

[31]. H. Glatvitsch and F. Alvarado, "Management of multiple congested conditions in unbundled operation of a power system," IEEE Transactions on Power Systems, vol. 13, no. 3,pp. 1013-1019, August 1998.

[32]. H.Chao and S. Peck, "A Market Mechanism for Electric Power Transmission", J Regu. Econ., Vol.10, July 1996, pp. 25-29.

[33]. P. Gribik , G.A. Angelidis and R.R. Kovacs, "Transmission Access and Pricing with Multiple Separate Energy Forward Markets", IEEE Transactions on Power Systems, Vol. 14, No. 3, August 1999, pp. 865-876.

[34]. S.Oren, P. Spiller, P. Varaiya and F.F.Wu, "Nodal Prices and Transmission Rights: A Critical Appraisal", POWER Report PWP-025, University of California Energy Institute, Berkeley, December 1994.

[35]. T. W. Gedra, "On Transmission Congestion and Pricing”, IEEE Transactions on Power Systems, Vol. 14, No. 1, February 1999, pp. 241-248. 